ISSN: 2577-1914

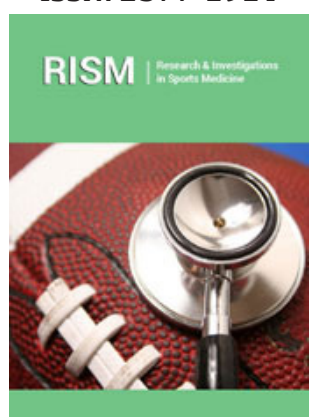

*Corresponding author: Cage SA, University of Texas at Tyler, University of North Carolina, USA

Submission: 留 May 08, 2020

Published: 眥June 02, 2020

Volume 6 - Issue 3

How to cite this article: $S$ Andrew $C$ Brandon W, David M, Warner L, et al. Attitudes and Moods among Athletic Trainers Following Suspension of 2020 Athletic Season Due to COVID-19. Res Inves Sports Med, 6(3): RISM.000640. 2020. DOI: $10.31031 /$ RISM.2020.06.000640

Copyright@ S Andrew C, This article is distributed under the terms of the Creative Commons Attribution 4.0 International License, which permits unrestricted use and redistribution provided that the original author and source are credited.

\section{Attitudes and Moods among Athletic Trainers Following Suspension of 2020 Athletic Season Due to COVID-19}

\author{
S Andrew $\mathrm{C}^{1,2 *}$, Brandon $\mathrm{W}^{2,3}$, David $\mathrm{M}^{3}$, Warner $\mathrm{L}^{4}$, Diana $\mathrm{G}^{1}$, Laurel $\mathrm{T}^{5}$, \\ Christina $\mathrm{T}^{6}$ and Julie $\mathrm{G}^{7}$ \\ ${ }^{1}$ University of Texas at Tyler, USA \\ ${ }^{2}$ University of North Carolina, Greensboro, USA \\ ${ }^{3}$ Grand Canyon University, USA \\ ${ }^{4}$ MVP Orthopedics, USA \\ ${ }^{5}$ Christus Trinity Mother Frances, USA \\ ${ }^{6}$ The University of Texas Health Science Center, USA \\ ${ }^{7}$ Collin College, USA
}

\section{Abstract}

Following the global spread of severe acute respiratory syndrome coronavirus 2 (SARS-CoV-2), the majority of colleges and high schools canceled all face-to-face courses and athletic activities. In response to these cancellations, the National Collegiate Athletics Association and National Junior College Athletics Association voted in favor of granting student-athletes who participated in spring sports and met certain criteria an extra year of eligibility. At this time, research is being conducted to evaluate the epidemiology, recognition, treatment and prevention of coronavirus disease 2019 (COVID-19), the disease associated with SARS-CoV-2. However, there does not appear to be any published research on the attitudes and motivations of the athletic trainers caring for student-athletes following the cancellations 2020 spring athletic and academic semesters. Therefore, the purpose of this pilot study is to describe the attitudes and moods of certified athletic trainers during the COVID-19 pandemic. A total of 284 certified athletic trainers participated in this study (age $=37 \pm 11$, certified experience $=13 \pm 10$ ). Participants were sent an electronic survey via email that collected demographic information and assessed attitudes and motivations regarding the shortened season and an extra year of eligibility. Data were downloaded and analyzed using a commercially available statistics package. The overwhelming majority of certified athletic trainers surveyed, in this study, were disappointed about the 2020 spring semester being shortened (Disappointed $=82.7 \%$ ). Additionally, the mean scores on the PHQ-9 and GAD-7 indicated that on average athletic trainers are currently experiencing symptoms of mild depression and/or anxiety. These two questionnaires are screening tools, and as such should not be used as the only criteria for diagnosing depression and anxiety. However, these scores do indicate that many athletic trainers would benefit from advanced mental healthcare during the COVID-19 pandemic. These findings also suggest that the mental health of athletic trainers should be a consideration as schools begin to make determinations about returning to campus and athletic activities.

\section{Introduction}

Coronavirus disease 19 (COVID-19) is an increasingly serious respiratory disease caused by severe acute respiratory syndrome coronavirus 2 (SARS-CoV-2) [1]. COVID-19 was first detected in December 2019 in Wuhan, China [1]. The disease has been found to be highly infectious and features symptoms including, fever, dry cough, fatigue, loss of smell, loss of taste, muscle and joint pain, and shortness of breath [1]. In advanced cases, patients have been reported as developing potentially fatal pneumonia, septic shock, metabolic acidosis, and coagulation dysfunction [2]. In the absence of a proven treatment or vaccine, the primary recommendations to mitigate the spread of COVID-19 has been social distancing, recognition through testing, contact tracing, and enhanced hygiene precautions $[3,4]$. 
As the COVID-19 pandemic advanced, more communities and organizations began making decisions in an attempt to slow the spread of COVID-19. To this end, the National Collegiate Athletic Association (NCAA) chose to cancel all remaining spring and winter championships [5]. After this decision was made, the majority of institutions and conferences chose to cancel the remainder of their seasons [6]. Given that student-athletes competing in spring sports had the majority of their seasons ended prematurely, due to these cancellations, the NCAA voted to provide student-athletes meeting certain criteria with an extra year of eligibility [7]. In addition to the cancellations made at higher education institutions, secondary schools also canceled or suspended athletic activities for the remainder of the 2020 spring semester [8]. Not only were athletic activities canceled, but the majority of higher education institutions and secondary schools in the United States canceled face-to-face learning as well $[9,10]$.

Currently, research is being conducted to evaluate the epidemiology, recognition, treatment and prevention of COVID-19 [1-4]. However, there does not appear to be any published research on the attitudes and moods of certified athletic trainers following the cancellations of athletic activities and face-to-face instruction for the 2020 spring semester. Thus, the purpose of this study is to describe the attitudes and moods of certified athletic trainers following the suspension of athletic activities and face-to-face instruction for the 2020 spring semester.

\section{Methods}

\section{Design}

This study was conducted using a cross-sectional design utilizing an internet-based survey for data collection.

\section{Participants}

Participants were recruited for this study by emailing the head athletic trainers at NCAA Division I, Division II, and Division III institutions, and Commission on Accreditation of Athletic Training Education (CAATE) accredited program directors. These individuals were also asked to send the survey invitation to any fellow staff members or preceptors associated with their programs. To ensure that an adequate number of high school athletic trainers were surveyed, invitations were also sent through the email groups for several regional athletic training professional organizations. A total of 284 participants (age $=37 \pm 11$, certified experience $=$ $13 \pm 10$ ) opened the survey link and completed the instrument. Demographic information for participants is presented in Table 1. All participants were informed of the survey's purpose and informed consent was obtained.

Table 1: Totals and percentages for participant demographic information.

\begin{tabular}{|c|c|c|}
\hline Demographic Factor & Criteria & Responses \\
\hline \multirow{2}{*}{ Sex } & Female & $166,58.5 \%$ \\
\hline & Male & $118,41.5 \%$ \\
\hline \multirow{5}{*}{ Clinical Practice Setting } & College/University & $223,78.5 \%$ \\
\hline & Secondary School & $48,16.9 \%$ \\
\hline & Clinic/Hospital & $9,3.2 \%$ \\
\hline & Emerging Settings & $3,1.1 \%$ \\
\hline & Professional Sports & $1,0.4 \%$ \\
\hline \multirow{6}{*}{ Highest Degree Earned } & Professional Bachelor's & $51,18 \%$ \\
\hline & Professional Master's & $62,21.8 \%$ \\
\hline & Post-Professional Masters (in Athletic Training) & $62,21.8 \%$ \\
\hline & Post-Professional Master's (not in Athletic Training) & $93,32.7 \%$ \\
\hline & Post-Professional Clinical Doctorate & $6,2.1 \%$ \\
\hline & Academic Doctorate & $10,3.5 \%$ \\
\hline
\end{tabular}

\section{Data collection}

An email was sent to head athletics trainers and CAATE accredited program directors at colleges and universities. These individuals were asked to complete the survey and to forward the message to any fellow athletic training staff members or preceptors they might work with. Survey invitations were also sent out through several regional athletic training organizations in an attempt to collect the most responses possible. The email included an invitation to participate in an electronic survey via a hyperlink from a web-based server (Qualtrics Inc., Provo, UT) from April to
May 2020. The inviting message contained information about the investigators, the purpose of the study, the nature of the survey, and assurances that the participants could opt to not complete the survey at any time. A follow-up email was sent a week after the initial email, and the survey was left open for a week prior to the survey being closed for statistical analysis.

\section{Instrument}

Following the informed consent and demographics section, the instrument contained items related to practice setting and hours 
spent performing athletic training-related duties before and during the COVID-19 pandemic stay home order. Other items gathered information on the attitudes of participants toward the shortened 2020 academic and athletic spring semester, as well as questions based on the PHQ-9 and GAD-7. These questionnaires ask patients to report attitudes, emotions, and activities based off how frequently they occur during a one-week period. Based off responses, the PHQ9 rates depression on a scale of No Depression, Mild Depression, Moderate Depression, Moderately Severe Depression and Severe Depression. The GAD-7 rates general anxiety on a scale of No Anxiety, Mild Anxiety, Moderate Anxiety, and Severe Anxiety. These questionnaires are valid methods for screening for symptoms of depression and general anxiety disorder respectively $[11,12]$.

The survey consisted of 34 total questions. These questions included: one question regarding consent to participate in the study, two fill in the blank and two multiple choice questions regarding demographic information, two fill in the blank questions regarding time spent on athletic training-related duties before and during the COVID-19 pandemic, 10 multiple choice questions regarding attitudes and emotions toward the shortened 2020 academic and athletic spring semester, and 14 multiple choice questions from the
PHQ-9 and GAD-7 intended to screen for symptoms of depression or general anxiety disorder.

\section{Statistical analysis}

Information from participant responses was downloaded and analyzed using a commercially-available statistics package (SPSS Version 26, IBM, Armonk, NY). A total of 284 athletic trainers responded and completed the study. All 284 responses were included in the data analysis. Measures of central tendency (means, standard deviations, frequencies) were calculated where appropriate.

\section{Results}

\section{Attitudes toward the shortened 2020 academic and athletic semester}

The majority of responding athletic trainers felt disappointed upon receiving the news that the 2020 semester had been ended prematurely $(82.7 . \%, n=235)$. More respondents reported feeling worse for their patients or the coaching staff they worked with than themselves. Table 2 provides a breakdown of the questions that gathered information on respondents' attitudes toward the shortened 2020 academic and athletic spring semester.

Table 2: Responses for questions on the emotions and attitudes experienced upon learning that the 2020 athletic and face-to-face academic spring semester had been canceled.

\begin{tabular}{|c|c|}
\hline Attitude/Emotion & Most Common Response (\%) \\
\hline Surprised & Agree, 73 (25.7\%) \\
\hline Stunned & Somewhat Agree, 59 (51.4\%) \\
\hline Excited & Disagree, 91 (32\%) \\
\hline Happy & Agree, 104 (36.6) \\
\hline Disappointed & Disagree, 84 (29.6\%) \\
\hline Angry & Neither Agree nor Disagree, $92(32.4 \%)$ \\
\hline Neither Positive Nor Negative $89(31.3 \%)$ and Strongly Disagree, $89(31.3 \%)$ \\
\hline I felt worse for myself. & Disagree, $121(42.6 \%)$ \\
\hline I felt worse for my patients. & Agree, $120(42.3 \%)$ \\
\hline I felt worse for the coaching staffs I work with. & Somewhat Agree, $94(33.1 \%)$ \\
\hline
\end{tabular}

\section{Depression \& general anxiety disorder}

Table 3: PHQ-9 and GAD-7 results among responding athletic trainers.

\begin{tabular}{|c|c|}
\hline Questionnaire & Scores (\%) \\
\hline & No Depression, 87 (30.6\%) \\
& Mild Depression, 95 (33.5\%) \\
PHQ - 9 & Moderately Depression, 52 (18.3\%) \\
& Moderately Severe Depression, 30 (10.6\%) \\
& Severe Depression, 20, (7\%) \\
\hline \multirow{3}{*}{ GAD-7 } & No Anxiety, 91 (32\%) \\
& Mild Anxiety, 98 (34.5\%) \\
& Moderate Anxiety, 66 (23.2\%) \\
& Severe Anxiety, 29 (10.2\%) \\
\hline
\end{tabular}

Out of the responding athletic trainers, $69.4 \%$ reported scores suggesting they were experiencing at least some level of depression $(n=197)$. Furthermore, the majority of respondents reported scores suggesting they were experiencing at least some level of general anxiety $(67.3 \%, \mathrm{n}=191)$. When means and standard deviations were taken, results suggested that on average athletic trainers were experiencing mild depression (PHQ-9 score $=8.22 \pm 6.39$ ) and mild anxiety (GAD-7 score $=6.97 \pm 5.47$ ). Table 3 provides a breakdown of these scores.

\section{Discussion}

The purpose of this study was to describe the attitudes, and moods of athletic trainers following the premature conclusion of athletic activities and face-to-face instruction for the 2020 spring. A secondary purpose was to anonymously screen athletic trainers for 
signs and symptoms of depression and anxiety during the current pandemic.

Our findings suggest that the majority of respondents surveyed were disappointed $(2.7 \%, \mathrm{n}=235)$ that the 2020 spring semester was altered. It is interesting to note that more respondents reported being disappointed rather than angry. Furthermore, athletic trainers reported feeling the worst for their patient population rather than themselves or the coaching staffs at their institutions. This suggests that some of the attitudes being experienced by athletic trainers might be due to sympathy for their patient population.

On average, athletic trainers reported experiencing signs and symptoms of mild depression (PHQ-9 score $=8.22 \pm 6.39$ ) and mild anxiety (GAD-7 score $=6.97 \pm 5.47$ ). It should be noted that the PHQ-9 and GAD-7 are screening tools, and should not be used as the only criteria for diagnosing depression or anxiety $[11,12]$. However, these findings suggest that the majority of athletic trainers would benefit from a diagnostic session with a mental healthcare professional to assess the need for therapeutic interventions.

A possible limitation of this study was the relatively low number of participants. While the total number of responses is similar or higher than other survey-based studies conducted on athletic trainers, an exhaustive and definitive statement on the psychosocial effects of the COVID-19 pandemic on athletic trainers would require a larger scale study $[13,14]$. However, the completion of this study provides a framework for conducting a study that collects data from a larger number of respondents. Another possible limitation was that a question was omitted from both the GAD-7 and PHQ-9 questionnaires. At the time, this was done in the interest of shortening the survey but may have led to some results not depicting the full extent of depression and anxiety being experienced by athletic trainers. Given that the GAD-7 and PHQ-9 rely on cumulative totals as opposed to averages, there is not a possibility that this omission led to more athletic trainers being identified for signs of depression and anxiety. Therefore, the authors believe that the reported results still suggest the need for further mental healthcare for athletic trainers in need at this time.

There is a need for additional research into the attitudes, moods, and psychosocial states of athletic trainers following the shortened 2020 academic and athletic spring semester. The cancellation of a spring semester of sports and face-to-face instruction is unprecedented, and as such requires examination of all potential implications. Future research could also be conducted on the role of the attitudes and moods of athletic trainers who have specific academic responsibilities such as teaching and advising following the premature end to the 2020 academic and athletic spring semester. The mental health of athletic trainers is a topic that has been previous studied as an area of concern by athletic training researchers $[15,16]$. As such, athletic trainers may be a population that warrants attention when stressful events occur within the area of athletics and sport.

\section{Conclusion}

In conclusion, the majority of surveyed athletic trainers were disappointed and/or angry about the 2020 spring semester being canceled. Although athletic trainers reported these negative emotions, they also stated they felt worse for their patients than they did for themselves or the coaching staffs at their institutions. Additionally, the majority of athletic trainers reported signs and symptoms that suggested the need for further screening for depression and anxiety. As athletic trainers, coaches, studentathletes, and administrators move forward it is important to consider the impact that the suspension of the 2020 spring semester has had on athletic trainers' attitudes, moods, and mental health. Consideration of these details may provide the opportunity to intervene should athletic trainers experience particularly negative emotions or moods.

\section{Acknowledgements}

The authors would like to thank Christina Decoteau for her assistance with conceptualizing this study.

\section{References}

1. Zhong BL, Luo W, Mei LH, Zhang QQ, Liu XG, et al. (2020) Knowledge, attitudes, and practices toward COVID-19 among Chinese residents during the rapid rise period of the COVID-19 outbreak: A quick online cross-sectional survey. International Journal of Biological Sciences 16(10): 1745-1752.

2. Chen N, Zhou M, Dong X, Qu J, Gong F, et al. (2020) Epidemiological and clinical characteristics of 99 cases of 2019 novel coronavirus pneumonia in Wuhan, China: A descriptive study. Lancet 395: 507-513.

3. Patel R, Babady E, Theel ES, Storch GA, Pinsky BA, et al. (2020) Report from the American Society for Microbiology COVID-19 International Summit, 23 March 2020: Value of diagnostic testing for SARS-CoV-2/ COVID-19. American Society for Microbiology 11(2).

4. Ebrahim SH, Memish ZA (2020) COVID-19 - The role of mass gatherings. Travel Med Infect Dis 34: 101617.

5. ESPN (2020) Coronavirus cancellations and reactions in sport.

6. ESPN (2020) SEC becomes latest conference to cancel sports for 20192020.

7. ESPN (2020) NCAA approves extra year of eligibility for spring athletes.

8. The New York Times. High school sports pushed out of bounds by the pandemic.

9. CNN (2020) Universities begin considering the possibility of cancelling in person classes until 2021.

10. The New York Times (2020) As schools look for guidance, educators are left asking, 'What?'.

11. Williams N (2014) Questionnaire Review: PHQ-9. Occupational Medicine 64(2): 139-140.

12. Plummer F, Manea L, Trepel D, McMillan D (2016) Screening for anxiety disorders with the GAD-7 and GAD-2: A systematic review and diagnostic metaanalysis. Gen Hosp Psychiatry 39: 24-31. 
13. Cage SA, Warner BJ, Gallegos DM, Fieseler C, Sims-Koenig K (2020) Characteristics of sickle cell trait policies and procedures at NCAA Division II Institutions. Research \& Investigations in Sports Medicine 6(1): 477-480.

14. Cage SA, Winkelmann ZK, Warner BJ, Gallegos DM (2020) Athletic Trainers' Perceived and Actual Knowledge of Cupping Therapy Concepts. Journal of Sports Medicine and Allied Health Sciences 5(3).
15. Kania, ML, Meyer BB, Ebersole KT (2009) Personal and environmental characteristics predicting burnout among certified athletic trainers at National Collegiate Athletic Association Institutions. J Athl Train 44(1): 58-66.

16. Estock P, Simon JE (2018) Prevalence and outcomes of exposure to catastrophic events among athletic trainers. J Athl Train 53(11): 10981102.

For possible submissions Click below: 